\title{
Clinical significance of monitoring ESR1 mutations in circulating cell-free DNA in estrogen receptor positive breast cancer patients
}

\author{
Takashi Takeshita ${ }^{1}$, Yutaka Yamamoto ${ }^{1}$, Mutsuko Yamamoto-Ibusuki ${ }^{2}$, Toko \\ Inao1, Aiko Sueta ${ }^{1}$, Saori Fujiwara', Yoko Omoto ${ }^{1,3}$, Hirotaka Iwase ${ }^{1}$ \\ ${ }^{1}$ Department of Breast and Endocrine Surgery, Graduate School of Medical Science, Kumamoto University, Chuo-ku, \\ Kumamoto, 860-8556, Japan \\ ${ }^{2}$ Department of Molecular-Targeting Therapy for Breast Cancer, Kumamoto University Hospital, Chuo-ku, Kumamoto, \\ 860-8556, Japan \\ ${ }^{3}$ Department of Endocrine and Breast Surgery, Graduate School of Medical Science, Kyoto Prefectural University of Medicine, \\ Hirokoji Agaru, Kawaramachi-dori, Kamigyo-ku, Kyoto, 602-0841, Japan
}

Correspondence to: Hirotaka Iwase, e-mail: hiwase@kumamoto-u.ac.jp

Keywords: estrogen receptor-positive metastatic breast cancer, acquired endocrine therapy resistance, cell-free DNA ESR1 mutations in plasma, droplet digital PCR

Received: January 11, 2016

Accepted: March 14, 2016

Published: April 19, 2016

\section{ABSTRACT}

Background: The measurement of circulating cell-free DNA (cfDNA) may transform the management of breast cancer patients. We aimed to investigate the clinical significance of sequential measurements of ESR1 mutations in primary breast cancer (PBC) and metastatic breast cancer (MBC) patients.

Results: ESR1 mutations ratio in the PBC groups was used as the minimum cutoff for determining increases in cfDNA ESR1 mutation ratio. An increase in cfDNA ESR1 mutations was found in 13 samples of cfDNA from $12(28.6 \%)$ out of 42 MBC patients. A total of $10(83.3 \%)$ out of $12 \mathrm{MBC}$ patients with increase cfDNA ESR1 mutations showed a poor response to treatment. In survival analysis, increase CfDNA ESR1 mutations may predict a shorter duration of post-endocrine-therapy effectiveness $(P=0.0033)$.

Methods: A total of 119 patients ( 253 plasma samples) with breast carcinoma were enrolled in this study. Cases were selected if archival plasma samples were available from PBC before and after treatment and from MBC gathered more than twice at the time of progression. cfDNA was isolated from the 77 PBC patients (154 plasma samples) and from the 42 MBC patients (99 plasma samples). To investigate any changes in each cfDNA ESR1 mutation before and after treatment, we analyzed the difference with cfDNA ESR1 mutations ratio in the first blood sample using droplet digital polymerase chain reaction (ddPCR).

Conclusions: We demonstrate that ddPCR monitoring of the recurrent ESR1 mutation in cfDNA of MBC patients is a feasible and useful method of providing relevant predictive information.

\section{INTRODUCTION}

In hormone receptor (HR)-positive metastatic breast cancer (MBC) without life-threating visceral metastases, aromatase inhibitors (AIs) or tamoxifen are the firstline treatments of choice because of their effectiveness balanced against their side effects [1]. However, all initially hormone-dependent breast cancers acquire anti- estrogen resistance after repeated endocrine therapies and, eventually, become hormone-independent [2]. Recently, ESR1-activating mutations have been postulated as the key potential mechanisms underlying the failure of endocrine therapies. ESR 1 mutations were first identified in patient xenograft studies reported almost two decades ago $[3,4]$ and next generation sequencing (NGS) studies revealed that ESR1 point mutations in a hot spot confined to Tyr537 
and Asp538 act as a driver of endocrine therapy resistance [5-8]. In particular, the representative four ESR1 ligand binding domain (LBD) "hot spot" mutations, ESR1 Y537S, Y537N, Y537C, and D538G, which cover more than $80 \%$ of ESR1 mutations associated with acquired resistance to antiestrogen therapy [5-7]. The detection of these mutations may be useful as biomarker of resistance to endocrine therapy and could help in choosing the most appropriate treatment for $\mathrm{HR}+\mathrm{MBC}$ [8-11]. In order to use ESR1 LBD mutations as biomarker for disease monitoring, the ESR1 genotyping should be performed whenever a disease progresses. However, when that is monitored by the tumor tissues, there are the following three limitations. Firstly, tumor biopsies are inconvenient from a scheduling perspective, especially when the tumor site is not easily accessible. Secondly, the method of sample preservation (e.g. formalin-fixed paraffinembedded) and intratumoral or intertumoral heterogeneity, also hamper the use of tumor tissue material. Finally, taking biopsies from tumor tissue always carries the risk of clinical complications [12].

Circulating cell-free DNA (cfDNA) analysis has been developed as a way of overcoming these limitations and providing relevant predictive information related to the tumor tissue [13-18]. In order for detection of cfDNA ESR 1 mutations to prove clinically useful, ESR 1 rare point mutations must be detected from small quantities of short lengths of DNA in plasma [19]. Droplet digital polymerase chain reaction (ddPCR) technology could solve this problem by means of its superior accuracy [20]. Technically, we had already evaluated the quantitative performance of ddPCR using four representative ESR1 LBD mutant molecules, ESR1 Y537S, Y537N, Y537C, and D538G in breast tumor tissue [21]. Additionally, using this assay, we could detect a small amount of cfDNA $P I K 3 C A$ major mutations in early-stage triple negative breast cancer [22].

In this retrospective study, we used ddPCR to investigate the clinical significance of tracking four representative types of ESR1 LBD mutations in 253 plasma samples from 119 breast cancer patients, of which 99 were from $42 \mathrm{MBC}$ patients and 154 were from 77 advanced ER-positive primary breast cancer (PBC) patients. To our knowledge, this is a leading study to evaluate the clinical significance of sequential measurements of ESR1 mutations in a large series of plasma samples from patients with $\mathrm{PBC}$ and $\mathrm{MBC}$.

\section{RESULTS}

\section{Patient characteristics}

A total of 119 patients (253 plasma samples) with breast carcinoma were enrolled in this study. A total of 77 women with $\mathrm{PBC}$ and 42 with $\mathrm{MBC}$ were evaluated. Of the 77 PBC patients, 17 were treated by neoadjuvant endocrine therapy (NET), 42 were treated by neoadjuvant chemotherapy (NAC), and 18 were not treated before surgery, but were treated by adjuvant therapy (AT) (Figure 1). To investigate changes in cfDNA ESR1 mutations following endocrine therapy or chemotherapy and adjuvant treatment for more than 5 years, we created subgroups of patients who treated by NET, NAC, and AT in the PBC group.

The patient demographics and baseline characteristics of PBC and MBC are presented in Table 1. The median age of the patients at first blood draw was 67 years (range, 41-82) in the NET group, 50 years (range, 31-70) in the NAC group, 62 years (range, 37-76) in the AT group, and 58 years (range, 31-82) in the MBC group. In the PBC groups, NAC patients had a higher stage, higher histological grade, lower ER $\alpha$ immunostaining, and positive Ki67 labeling index (LI). Of the primary clinical stage MBC patients, 16 patients $(38.1 \%)$ were categorized as stage IV and a total of 14 out of 42 cases $(33.3 \%)$ were not treated before first blood sampling. A total of 2 out of $42 \mathrm{MBC}$ cases were not treated until second blood draw because one had a past history of cerebral infarction and the other had microinvasive disease. The median duration of follow-up was 33 months (range, 13-101 months) in the NET group, 43.5 months (range, 17-118 months) in the NAC group, 77 months (range, 66-113 months) in the AT group, and 40 months (range, 9-129 months) in the MBC group. There was no recurrence during the observation period in any of the PBC patients.

\section{Tracking cfDNA ESR1 mutations analysis in breast cancer patients}

cfDNA was isolated from 154 plasma samples from the 77 PBC patients and from 99 plasma samples from the $42 \mathrm{MBC}$ patients. Plasma was collected at more than two points of the clinical course in all patients (three points in a total of $11(26.1 \%)$ and four points in a total of $4(9.5 \%)$ out of 42 MBC patients). As we expected, the median concentration of cfDNA was the highest in the MBC group (data not shown). In consecutive analysis of cfDNA ESR1 mutations, we should take the following 3 things into account. Firstly, breast cancer cells with ESR1 LBD mutations can survive and breast cancer cells with ESR1 wild-type cannot survive by endocrine therapy $[3-7,23]$. Secondly, the cfDNA extraction kit extracted DNA from plasma without distinction of double strand DNA and single strand DNA and they were parsed by one strand DNA by ddPCR. Finally, somatic mutations are present in commonly single base-pair substitutions. Therefore, we thought the allelic ratios of mutant to wild type ESR 1 were more precise biomarker than the absolute quantification or frequency of ESR 1 mutations. The ratio of mutation to wild type for the 4 ESR 1 mutations for the 1 st and the 2nd blood draw in this series is shown in Figure $\mathrm{S} 1$. In the 1st blood draw, there was no 
significant difference between the PBC group and the MBC group. However, in the 2nd blood draw, cfDNA ESR1 Y537S ratio in the MBC group was significantly higher than that in the NAC and the AT group $(P=0.031$ and 0.038 , respectively), and cfDNA ESR 1 D538G ratio was significantly higher than that in the NET group $(P=0.032)$.

The paired analysis to compare pre- and posttreatment cfDNA ESR1 mutation ratio allowed us to establish if there was a change in cfDNA ESR 1 mutations ratio in the transition from treatmentsensitive to -refractory disease for each individual patient. ESR 1 mutation tracking in cfDNA in PBC and $\mathrm{MBC}$ patients and the difference with each cfDNA ESR1 mutation ratio of the first blood draw (ESR1 Y537S, Y537N, Y537C, and D538G) are shown in Figure 2. By

A

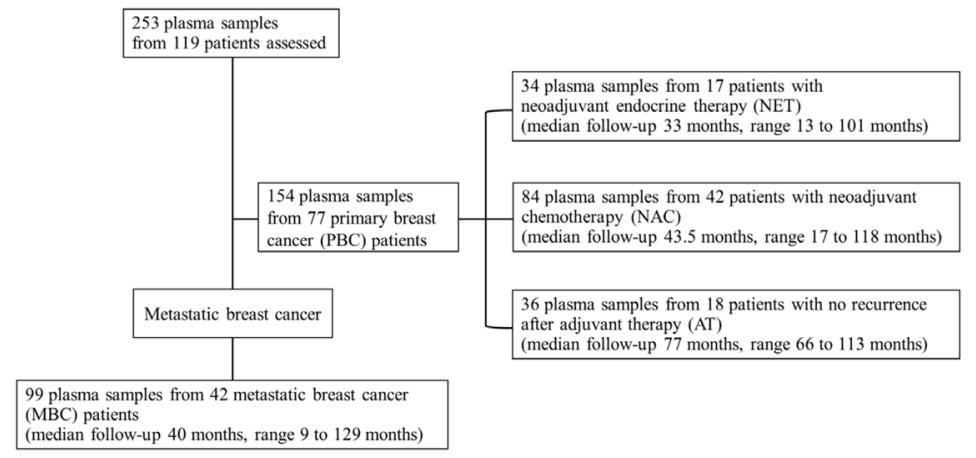

B

Metastatic breast cancer (MBC)

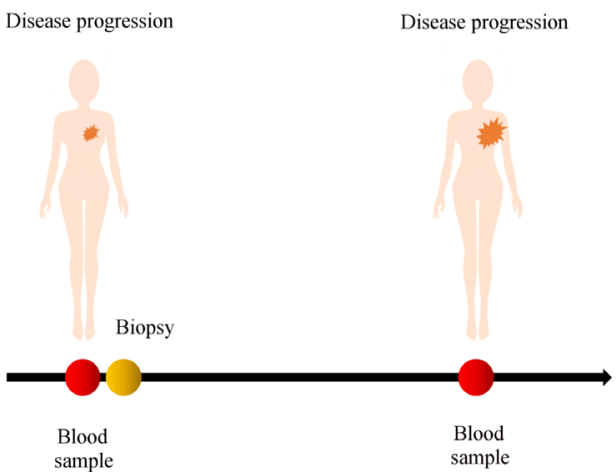

examining the difference with cfDNA ESR1 mutations ratio in the first blood draw for each patient, we were able to create subgroups of patients whose cfDNA ESR1 mutations ratio exhibited either an increase or not in all patients. All samples were compared with the ESR 1 wild-type molecule and each ESR 1 mutant molecule as positive control. A water only (no template) control was run in parallel for each ddPCR reaction as negative control. An increase in cfDNA ESR 1 Y 537S ratio was statistically significant in the MBC group compared with the AT group $(P=0.0045)$, but there was no significant difference in ESR 1 Y 537N, ESR1 Y537C, and ESR1 D538G between all $\mathrm{PBC}$ groups and the MBC group. ESR1 mutations ratio tended to be increased in the $\mathrm{MBC}$ group compared with the other PBC groups (Figure S2). We established a cut-off value of the increase in cfDNA ESR1 mutations

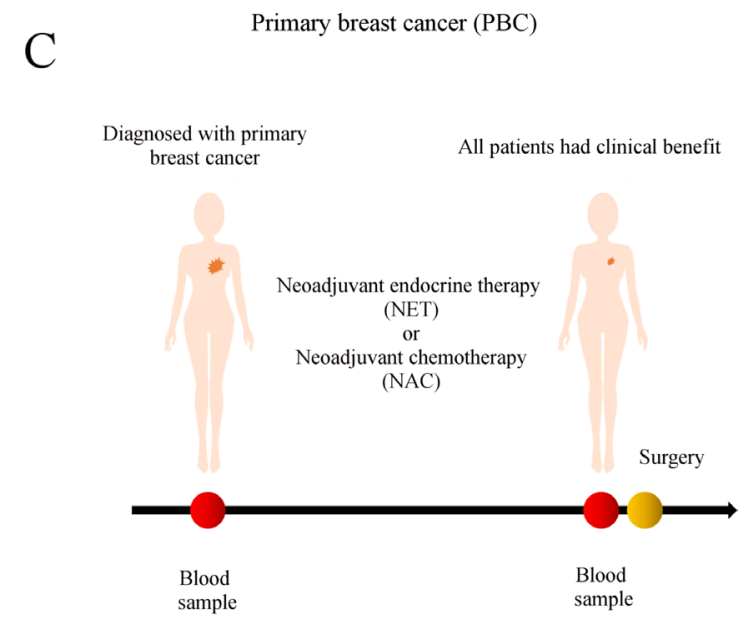

$\mathrm{D}$

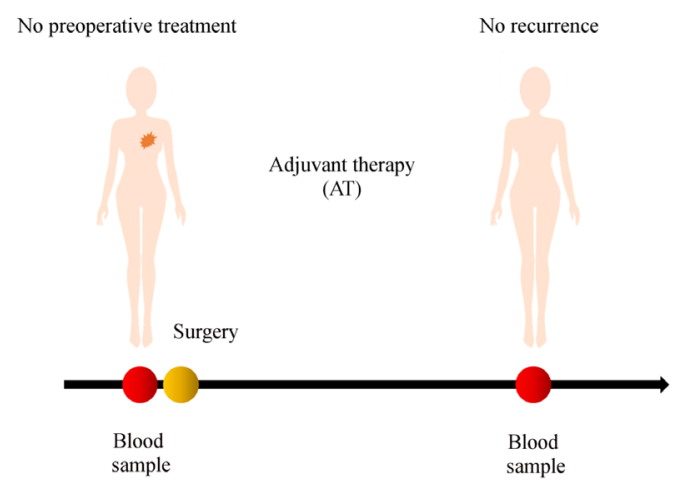

Figure 1: (A) Schematic representation of the study protocol (B-D). Study schema. For 119 women with breast cancer, personalized droplet digital PCR assays were used to quantify ESR1 DNA sequences in the circulating cell-free DNA (cfDNA) isolated from 253 patient blood plasma samples taken serially during the clinical course. cfDNA was isolated from 154 plasma samples from the 77 primary breast cancer (PBC) patients and (B) 99 plasma samples from the 42 metastatic breast cancer (MBC) patients. In 77 PBC patients, (C) 17 patients were treated by neoadjuvant endocrine therapy (NET), (C) 42 patients were treated by neoadjuvant chemotherapy (NAC), and (D) 18 patients were treated by adjuvant therapy only (AT). We analyzed how cfDNA ESR 1 mutations change following endocrine therapy or chemotherapy by comparing the NET group with the NAC group. We also investigated how cfDNA ESR1 mutations change following tumor resection by comparing the AT group with the other PBC groups. 
Table 1: Patient characteristics

\begin{tabular}{|c|c|c|c|c|c|}
\hline \multirow[b]{3}{*}{ Variables } & \multirow[b]{3}{*}{ Total } & \multicolumn{3}{|c|}{ No. of samples (\%) } & \multirow{3}{*}{ MBC } \\
\hline & & \multicolumn{3}{|c|}{ Primary breast cancer } & \\
\hline & & NET & NAC & AT & \\
\hline & $(N=119)$ & $(N=17)$ & $(N=42)$ & $(N=18)$ & $(N=42)$ \\
\hline \multicolumn{6}{|l|}{ Age at biopsy } \\
\hline Median (range) & $58(31-82)$ & $67(41-82)$ & $50(31-70)$ & $62(37-76)$ & $58(31-82)$ \\
\hline \multicolumn{6}{|l|}{ Primary clinical Stage } \\
\hline $\mathrm{I}$ & $26(21.8)$ & $4(23.5)$ & $1(2.4)$ & $14(77.8)$ & $7(16.7)$ \\
\hline II & $59(49.6)$ & $11(64.7)$ & $29(69)$ & $4(22.2)$ & $15(35.7)$ \\
\hline III & $17(14.3)$ & $2(11.8)$ & $12(28.6)$ & 0 & $4(9.5)$ \\
\hline IV & $17(14.3)$ & 0 & 0 & 0 & $16(38.1)$ \\
\hline \multicolumn{6}{|l|}{ Histological type } \\
\hline Invasive ductal & $113(95)$ & $13(76.5)$ & $42(100)$ & $18(100)$ & $40(95.2)$ \\
\hline Invasive lobular & $3(2.5)$ & $1(5.9)$ & 0 & 0 & $2(4.8)$ \\
\hline Mucinous & $3(2.5)$ & $3(17.6)$ & 0 & 0 & 0 \\
\hline \multicolumn{6}{|l|}{ Histological grade } \\
\hline 1 & $45(37.8)$ & $5(29.4)$ & $10(23.8)$ & $12(66.7)$ & $18(42.9)$ \\
\hline 2 & $51(42.9)$ & $11(64.7)$ & $22(52.4)$ & $6(33.3)$ & $12(28.6)$ \\
\hline 3 & $20(16.8)$ & 0 & $10(23.8)$ & 0 & $10(23.8)$ \\
\hline Lobular & $3(2.5)$ & $1(5.9)$ & 0 & 0 & $2(4.8)$ \\
\hline $\begin{array}{l}\text { The percentage of ER } \alpha \\
\text { median }(25 \%, 75 \%)\end{array}$ & $119(100)$ & $90(90-95)$ & $85(60-90)$ & $90(80-91.3)$ & $90(70-95)$ \\
\hline $\begin{array}{l}\text { The percentage of PgR } \\
\text { median }(25 \%, 75 \%)\end{array}$ & $119(100)$ & $50(7.5-85)$ & $45(5-82.5)$ & $55(20-90)$ & $30(0.75-70)$ \\
\hline \multicolumn{6}{|l|}{ HER2 } \\
\hline Negative & $16(13.4)$ & $16(94.1)$ & $34(80.1)$ & $17(94.4)$ & $36(85.7)$ \\
\hline Positive & $103(86.6)$ & $1(5.9)$ & $8(19.1)$ & $1(5.6)$ & $6(14.3)$ \\
\hline \multicolumn{6}{|l|}{ Ki67 LI } \\
\hline$\leq 14$ & $54(45.4)$ & $15(88.2)$ & $11(26.2)$ & $7(38.9)$ & $21(50)$ \\
\hline$>14$ & $35(29.4)$ & $2(11.8)$ & $20(47.6)$ & $1(5.5)$ & $12(28.6)$ \\
\hline Unknown & $30(25.2)$ & 0 & $11(26.2)$ & $10(55.6)$ & $9(21.4)$ \\
\hline \multicolumn{6}{|c|}{ Therapy change: number of times before first blood sampling } \\
\hline 0 & & & & & $14(33.3)$ \\
\hline 1 & & & & & $13(31)$ \\
\hline 2 & & & & & $2(4.8)$ \\
\hline 4 & & & & & $3(7.1)$ \\
\hline 5 & & & & & $1(2.4)$ \\
\hline 6 & & & & & $2(4.8)$ \\
\hline 8 & & & & & $1(2.4)$ \\
\hline 9 & & & & & $3(7.1)$ \\
\hline 10 & & & & & $1(2.4)$ \\
\hline 12 & & & & & $2(4.8)$ \\
\hline
\end{tabular}




\begin{tabular}{|c|c|c|c|c|c|}
\hline $\begin{array}{l}\text { Treatment before first } \\
\text { blood sampling }\end{array}$ & & & & & \\
\hline $\mathrm{AI}$ & $10(8.4)$ & 0 & 0 & 0 & $10(23.8)$ \\
\hline SERM & $4(3.4)$ & 0 & 0 & 0 & $4(9.5)$ \\
\hline Others & $3(2.5)$ & 0 & 0 & 0 & $3(7.1)$ \\
\hline Chemotherapy & $11(9.2)$ & 0 & 0 & 0 & $11(26.2)$ \\
\hline None & $91(76.5)$ & $17(100)$ & $42(100)$ & $18(100)$ & $14(33.3)$ \\
\hline \multicolumn{6}{|l|}{$\begin{array}{l}\text { Treatment after first } \\
\text { blood sampling }\end{array}$} \\
\hline $\mathrm{AI}$ & $29(24.4)$ & $17(100)$ & 0 & 0 & $12(28.6)$ \\
\hline SERM & $8(6.7)$ & 0 & 0 & 0 & $8(19)$ \\
\hline Others & $6(5)$ & 0 & 0 & 0 & $6(14.3)$ \\
\hline Chemotherapy & $56(47.1)$ & 0 & $42(100)$ & 0 & $14(33.3)$ \\
\hline None & $20(16.8)$ & 0 & 0 & $18(100)$ & $2(4.8)$ \\
\hline \multicolumn{6}{|l|}{$\begin{array}{l}\text { Treatment before second } \\
\text { blood sampling }\end{array}$} \\
\hline $\mathrm{AI}$ & $29(24.4)$ & $17(100)$ & 0 & 0 & $12(28.6)$ \\
\hline SERM & $7(5.9)$ & 0 & 0 & 0 & $7(16.7)$ \\
\hline Other endocrine therapy & $9(7.6)$ & 0 & 0 & 0 & $9(21.4)$ \\
\hline Chemotherapy & $54(45.4)$ & 0 & $42(100)$ & 0 & $12(28.6)$ \\
\hline None & $20(16.8)$ & 0 & 0 & $18(100)$ & $2(4.8)$ \\
\hline \multicolumn{6}{|l|}{$\begin{array}{l}\text { Treatment after second } \\
\text { blood sampling }\end{array}$} \\
\hline $\mathrm{AI}$ & $55(46.2)$ & $16(94.1)$ & $15(35.7)$ & $10(55.6)$ & $14(33.3)$ \\
\hline SERM & $29(24.4)$ & 0 & $19(45.2)$ & $2(11.1)$ & $8(19.1)$ \\
\hline Other endocrine therapy & $10(8.4)$ & 0 & 0 & 0 & $10(23.8)$ \\
\hline Chemotherapy & $25(21.0)$ & $1(5.9)$ & $8(19.1)$ & $6(33.3)$ & $10(23.8)$ \\
\hline None & 0 & 0 & 0 & 0 & 0 \\
\hline \multicolumn{6}{|l|}{$\begin{array}{l}\text { Treatment after third } \\
\text { blood sampling }\end{array}$} \\
\hline $\mathrm{AI}$ & & & & & 0 \\
\hline SERM & & & & & $1(9.1)$ \\
\hline Other endocrine therapy & & & & & $4(36.4)$ \\
\hline Chemotherapy & & & & & $6(54.6)$ \\
\hline None & & & & & 0 \\
\hline \multicolumn{6}{|l|}{$\begin{array}{l}\text { Treatment after fourth } \\
\text { blood sampling }\end{array}$} \\
\hline AI & & & & & 0 \\
\hline SERM & & & & & 0 \\
\hline Other endocrine therapy & & & & & $1(25)$ \\
\hline Chemotherapy & & & & & $3(75)$ \\
\hline None & & & & & 0 \\
\hline
\end{tabular}

Abbreviations: NET, neoadjuvant endocrine therapy; NAC, neoadjuvant chemotherapy; AT, adjuvant therapy; MBC, metastatic breast cancer; ER $\alpha$, estrogen receptor alpha; PgR, progesterone receptor; HER2, human epidermal growth factor receptor 2; LI, labeling index; SERM, selective estrogen receptor modulator. 
based on PBC groups. Therefore, we set 0.4055 ratios gain compared with that in the first blood sample for the cut-off level of increasing cfDNA ESR1 mutations ratio. According to the selected cut-off point, we identified 13 increases in cDNA ESR 1 mutations during treatment from $12(28.6 \%)$ out of $42 \mathrm{MBC}$ patients; detailed descriptions of these patients are given in Figure $3 \mathrm{~A}$ and Table 2. Systemic endocrine therapy was administered, although many patients also received prior chemotherapy. Among these 12 patients, 6 patients $(50 \%)$ each had increasing cfDNA ESR 1 Y537S and Y537N, and 2 patients (16.7\%) had increasing cfDNA ESR1 D538G. Interestingly, 1 patient had 2 increasing cfDNA ESR 1 mutations, Y537S/ D538G. Interestingly, a total of $10(83.3 \%)$ out of $12 \mathrm{MBC}$ patients with increasing ESR1 mutations were not response to any treatments (Figure 3A). In this study we were able to analyze, cfDNA ESR1 mutations in serial samples from tumor tissues of 14 out of the total of $42 \mathrm{MBC}$ patients. Two out of these14 patients had ESR1 mutations
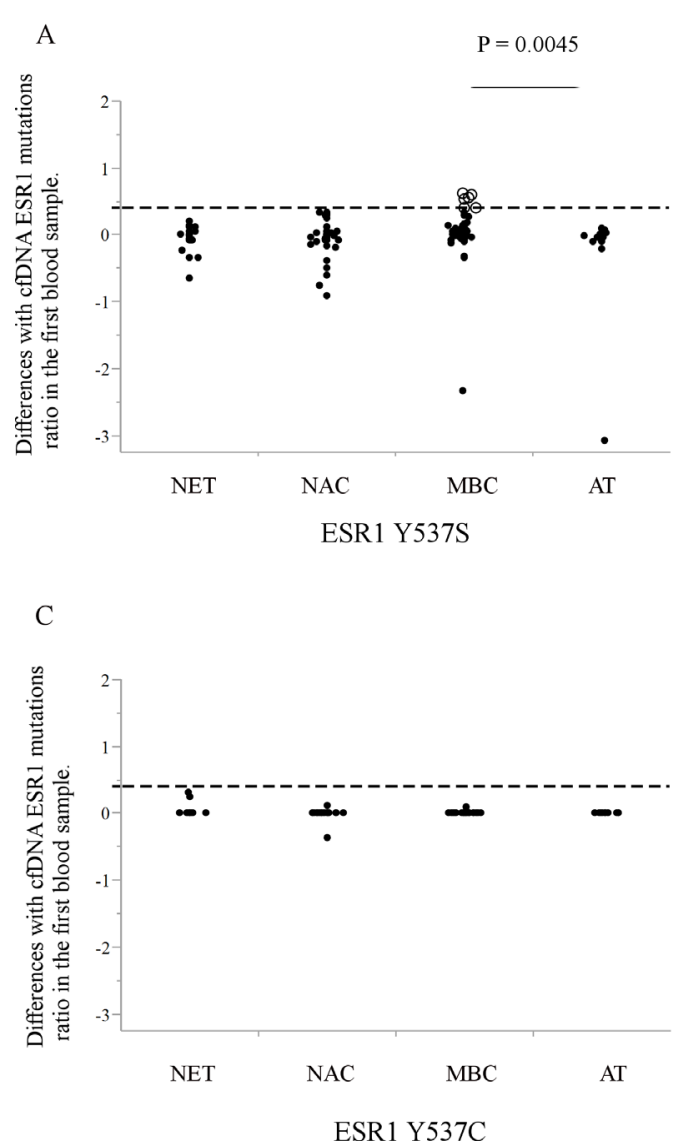

in tumor tissue, but did not show an increase in cfDNA ESR 1 mutations. In contrast, six out of the 14 patients did not have ESR1 mutations in the tumor tissue, but did show increases in cfDNA ESR 1 mutations.

\section{Survival analysis of the $42 \mathrm{MBC}$ patients}

Patients were grouped according to whether or not cfDNA ESR 1 mutations increased, and groups were compared by the patient response end points of time-totreatment failure (TTF) and breast cancer-specific survival (BCSS) (Figure 3B, 3C). In the analysis of TTF, local recurrences, distant metastases, and disease progression at any site following blood sampling were considered as an event. In the analysis of BCSS, a total of 17 patients died of breast cancer, and these deaths were considered events. These were tested by Kaplan-Meier analysis and verified by the log-rank test. In TTF analysis, patients with no increase in cfDNA ESR 1 mutations had a longer



$\mathrm{D}$

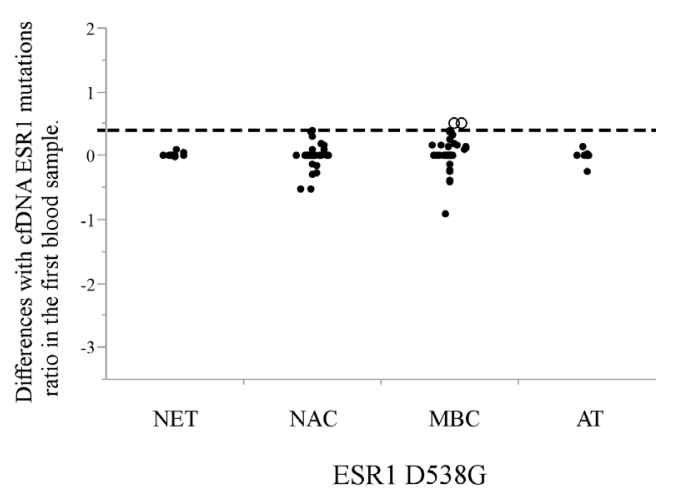

Figure 2: (A-D) The ratio of post-treatment to pre-treatment for each cfDNA ESR1 mutation (A; ESR1 Y537S, B; Y537N, C; Y537C, and D; D538G) are shown. All samples were measured with ESR1 wild-type molecule and each ESR1 mutant molecule as positive control. A water only (no template) control was run in parallel for each ddPCR reaction as negative control. ESRI mutations tended to be higher in the MBC group compared with other PBC groups. Whether cfDNA ESR1 mutations ratio after treatment was increased or not, we set 0.4055 ratios gain compared with that in the first blood sample for the cut-off level of increasing cfDNA ESR1 mutations ratio that we cannot identify in the other PBC groups (broken line shows cut-off line and open circles show cases with increasing ESR 1 mutations ratio). Using this selected cut-off point, we identified 13 increases in cfDNA ESR1 mutations ratio during the treatment period from 12 (28.6\%) out of $42 \mathrm{MBC}$ patients. Abbreviations; cfDNA, cell-free DNA; ddPCR, droplet digital polymerase chain reaction; MBC, metastatic breast cancer; PBC, primary breast cancer. 
Table 2: Patient characteristics of 12 ER-positive metastatic breast cancer cases with increasing cell-free DNA ESR1 mutations

\begin{tabular}{|c|c|c|c|c|c|c|c|c|c|c|c|}
\hline \multirow[b]{2}{*}{ Case } & \multirow{2}{*}{$\begin{array}{l}\text { Age at } \\
\text { first } \\
\text { blood } \\
\text { draw }\end{array}$} & \multirow{2}{*}{$\begin{array}{c}\text { Primary } \\
\text { ER/PgR/ } \\
\text { HER2/ } \\
\text { Ki67 }\end{array}$} & \multirow{2}{*}{$\begin{array}{l}\text { Primary } \\
\text { clinical } \\
\text { stage }\end{array}$} & \multirow{2}{*}{$\begin{array}{l}\text { Metastatic } \\
\text { ER/PgR/ } \\
\text { HER2/Ki67 }\end{array}$} & \multirow{2}{*}{$\begin{array}{l}\text { Site of } \\
\text { tissue } \\
\text { biopsy }\end{array}$} & \multicolumn{3}{|c|}{ Increasing cfDNA ESRI mutation } & \multirow[b]{2}{*}{ Treatment } & \multirow{2}{*}{$\begin{array}{l}\text { Treatment } \\
\text { after } \\
\text { increasing } \\
\text { cfDNA } E S R 1 \\
\text { mutation }\end{array}$} & \multirow{2}{*}{$\begin{array}{c}\text { BOR to } \\
\text { treatment } \\
\text { after } \\
\text { increasing } \\
\text { cfDNA } \\
\text { ESRI } \\
\text { mutation }\end{array}$} \\
\hline & & & & & & $\begin{array}{l}\text { 2nd blood } \\
\text { draw }\end{array}$ & $\begin{array}{l}\text { 3rd blood } \\
\text { draw }\end{array}$ & $\begin{array}{l}\text { 4th blood } \\
\text { draw }\end{array}$ & & & \\
\hline 18 & 66 & unknown/ & I & $90 / 60 /-/ 6$ & Lung & Y537S & $\begin{array}{c}\text { No } \\
\text { elevating } \\
\text { ESRI } \\
\text { mutations }\end{array}$ & $\begin{array}{c}\text { No } \\
\text { elevating } \\
\text { ESRI } \\
\text { mutations }\end{array}$ & \begin{tabular}{|c|} 
Fadrozole, chemotherapy, \\
Letrozole, Toremifene, Anastrozole, \\
MPA, Nab-Paclitaxel, Exemestane, \\
Epirubicine+Cyclophosphamide,
\end{tabular} & Letrozole & PD \\
\hline 27 & 31 & $70 / 5 /-15$ & IIA & $70 / 60 /-/ 5$ & $\begin{array}{c}\text { Lymph } \\
\text { node }\end{array} \mid$ & Y537S & - & 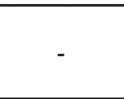 & $\begin{array}{l}\text { FEC } \rightarrow \text { docetaxel, Zoladex, } \\
\text { Goserelin acetate+Tamoxifen, } \\
\text { Goserelin acetate+Anastrozole }\end{array}$ & $\begin{array}{l}\text { Goserelin } \\
\text { acetate+ } \\
\text { Anastrozole }\end{array}$ & PD \\
\hline 44 & 58 & - & IV & $90 / 0 /-/ 5$ & Breast & D538G & $\begin{array}{l}\text { No } \\
\text { elevating } \\
\text { ESRI } \\
\text { mutations }\end{array}$ & - & $\begin{array}{c}\text { Anthracyclin+Cyclophosphamide, } \\
\text { Trastuzumab, Letrozole, } \\
\text { HdTOR+Trastuzumab, } \\
\text { Exemestane+Trastuzumab, Nab- } \\
\text { Paclitaxel+Trastuzumab, Letrozole, } \\
\text { EE2, Fulvestrant } \\
\end{array}$ & Fulvestrant & PD \\
\hline 53 & 40 & - & IV & $90 / 20 /-/ 1$ & Ovary & Y537S & - & - & \begin{tabular}{|c|} 
Exemestane, Paclitaxel, Letrozole, \\
HdTOR, Capecitabine, Anastrozole, \\
Docetaxel, Vinorelbine, \\
Mitoxantrone+Mitomycin \\
C+Methotrexate, Gemcitabine
\end{tabular} & $\begin{array}{l}\text { Mitoxantrone } \\
\text { Mitomycin C } \\
\text { Methotrexate }\end{array}$ & PD \\
\hline 58 & 60 & - & IV & $90 / 90 /-/ 10$ & Bone & $\begin{array}{c}\text { No } \\
\text { elevating } \\
\text { ESRl } \\
\text { mutations }\end{array}$ & Y537S & $\begin{array}{l}\text { No } \\
\text { elevating } \\
\text { ESRI } \\
\text { mutations }\end{array}$ & $\begin{array}{c}\text { Letrozole+Goserelin } \\
\text { acetate,Tamoxifen, Exemestane, } \\
\text { Adriamycin+Cyclophosphamide, } \\
\text { Docetaxel, Paclitaxel, } \\
\text { Mitoxantrone+Mitomycin C } \\
\text { +Methotrexate } \\
\end{array}$ & Paclitaxel & PD \\
\hline 62 & 67 & $60 / 5 /-/ 10$ & IIB & $5 / 0 /-/ 30$ & $\begin{array}{c}\text { Lymph } \\
\text { node }\end{array}$ & Y537S & - & - & $\begin{array}{c}\text { Docetaxel+Cyclophosphamide, } \\
\text { Letrozole } \times 4 \text { years, Fulvestrant, } \\
\text { Bevacizumab+Paclitaxel, } \\
\text { Tamoxifen } \\
\end{array}$ & Fulvestrant & PD \\
\hline 72 & 61 & $\begin{array}{c}80 / 60 /- \\
/ 10\end{array}$ & IIIA & $90 / 80 /-/ 2$ & Skin & $\mathrm{Y} 537 \mathrm{~N}$ & - & - & $\begin{array}{l}\text { FEC, Anastrozole, Exemestane, } \\
\text { HdTOR, Letrozole, EE2 }\end{array}$ & EE2 & PR \\
\hline 75 & 61 & $90 / 60 /-$ & IIIA & $90 / 0 /-/ 20$ & Skin & $\begin{array}{c}\text { No } \\
\text { elevating } \\
\text { ESR1 } \\
\text { mutations }\end{array}$ & Y $537 \mathrm{~N}$ & Y $537 \mathrm{~N}$ & $\begin{array}{c}\text { CMF, Docetaxel, } \\
\text { S-1+Anastrozple, Exemestane, } \\
\text { Epirubicine+Cyclophosphamide, } \\
\text { Docetaxel, Letrozole, } \\
\text { EE2, Letrozole, EE2, } \\
\text { Letrozole, Fulvestrant, } \\
\text { Exemestane+everolimus }\end{array}$ & $\begin{array}{l}\text { Fulvestrant/ } \\
\text { Exemestane } \\
\text { +everolimus }\end{array}$ & $\mathrm{PD} / \mathrm{SD}$ \\
\hline 77 & 48 & - & IV & $10 / 0 / 1+/ 3$ & Bone & $\begin{array}{c}\text { No } \\
\text { elevating } \\
\text { ESRl } \\
\text { mutations }\end{array}$ & $\begin{array}{l}\text { Y537S/ } \\
\text { D538G }\end{array}$ & - & \begin{tabular}{|c|} 
CEF $\rightarrow$ Docetaxel, Exemestane, \\
Fulvestrant, Goserelin \\
acetate+Anastrozole, \\
HdTOR, MPA, \\
Capecitabine+Cyclophosphamide, \\
Letrozole, Vinolrelbine, HdTOR, \\
Paclitaxel, Docetaxel \\
\end{tabular} & Docetaxel & PD \\
\hline 89 & 58 & unknown & I & $90 / 0 /-/ 10$ & Breast & $\begin{array}{l}\text { No } \\
\text { elevating } \\
\text { ESRl } \\
\text { mutations }\end{array}$ & Y537N & & $\begin{array}{c}\text { Goserelin acetate+Tamoxifen, } \\
\text { MitomycineC+Fluorouracil } \\
\text { +Epirubicine, Docetaxel, } \\
\text { Goserelin acetate+Tamoxifen, } \\
\text { Goserelin acetate+Anastrozole, } \\
\text { Goserelin acetate+Letrozole, } \\
\text { S-1, Vinoreline, Nab-Paclitaxel, } \\
\text { Exemestane, EE2, Letroozole, } \\
\text { Fulvestrant }\end{array}$ & Fulvestrant & PD \\
\hline 101 & 68 & $70 / 0 /-/ 15$ & I & $100 / 10 /-/ 30$ & Lung & Y537N & - & - & Letrozole, Toremifene, HdTOR, & HdTOR & $\mathrm{SD}$ \\
\hline 118 & 56 & $-/+/-1$ & IIA & $90 / 80 /-/ 5$ & $\begin{array}{c}\text { Lymph } \\
\text { node }\end{array}$ & Y $537 \mathrm{~N}$ & $\begin{array}{l}\text { No } \\
\text { elevating } \\
\text { ESRI } \\
\text { mutations }\end{array}$ & - & \begin{tabular}{|c|} 
Adriamycine+Cyclophosphamide, \\
Anastrozole, Exemestane, \\
Letrozole, Docetaxel, Capecitabine, \\
Letrozole, Exemestane, EE2, \\
Letrozole, EE2
\end{tabular} & EE2 & PR \\
\hline
\end{tabular}

Abbreviations: ER, estrogen receptor; PgR, progesteron receptor; HER2, human epidermal growth factor receptor 2; BOR, best overall response; FEC, Fluorourasil+epirubicine+ cyclophosphamide; HdTOR, high dose toremifene; EE2, ethinylestradiol; CEF, cyclophosphamide+epirubicine+fluorouracil; MPA, medroxyprogesterone acetate; S-1, an oral fluoropyrimidine; PR, partial response; SD, stable disease; PD, progressive disease. 
A

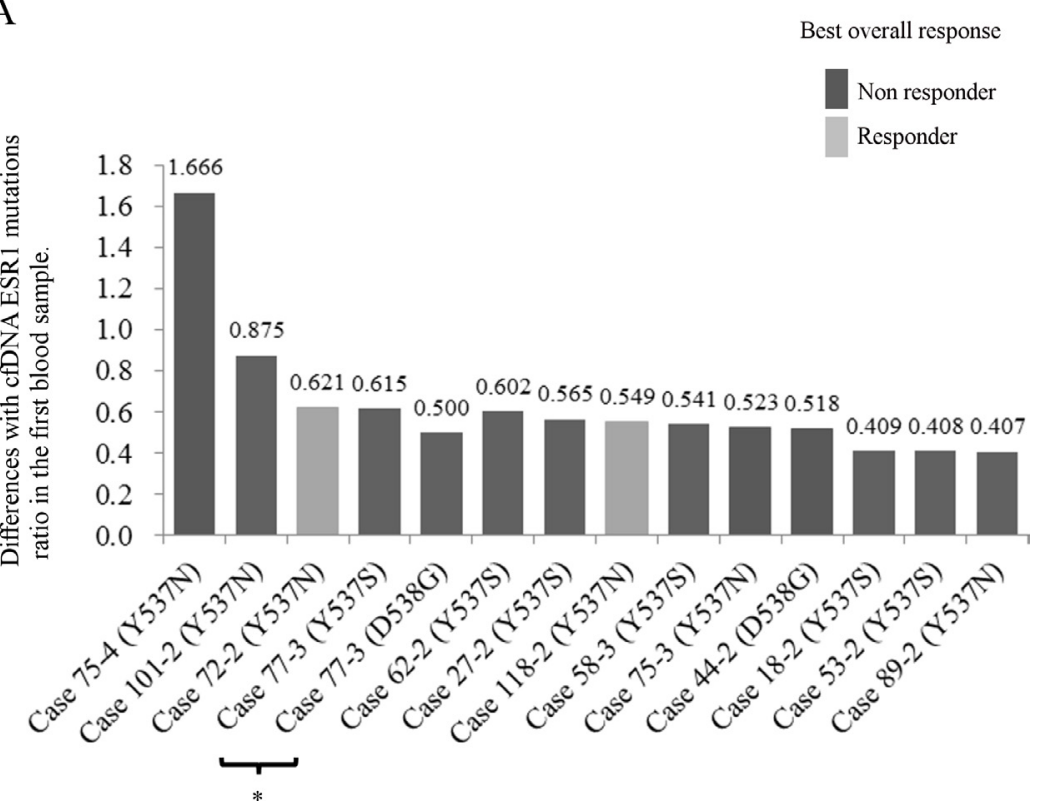

$\mathrm{B}$

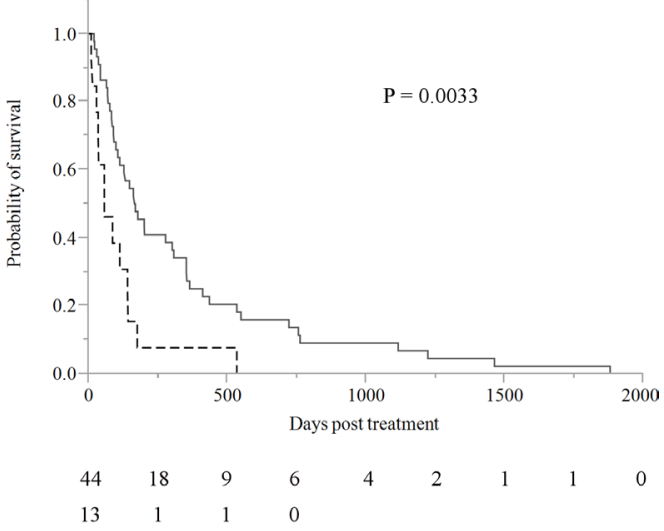

$\mathrm{C}$

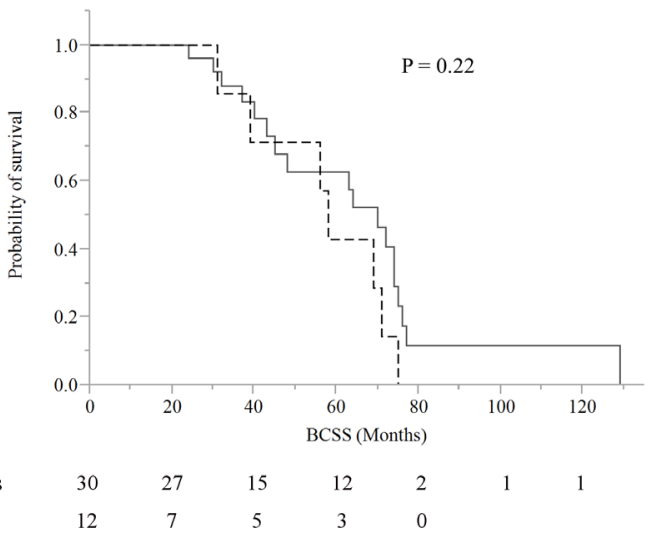

Figure 3: (A) The differences with cfDNA ESR1 mutations ratio in the first blood sample in 13 samples with increasing cfDNA ESR1 mutations from 12 out of $42 \mathrm{MBC}$ patients are shown according to the response to treatment. Black and gray bars represent response and non-response cases, respectively. *Same sample had increasing cfDNA ESR1 Y537S and D538G (B, C) KaplanMeier plots of the association of increases in cfDNA ESR1 mutations with (B) TTF and (C) BCSS in 42 MBC patients. When increasing cfDNA ESR 1 mutations were defined as either positive or negative using the selected cut-off, positive cases seemed to have a shorter duration of post-treatment effectiveness than negative ones in log-lank tests $(P=0.0033)$. A total of 3 out of 12 patients with increasing cfDNA ESR1 mutations were treated by chemotherapy. In BCSS analysis, there was no significant difference among the patients with and without increasing cfDNA ESR1 mutations $(P=0.22)$. Abbreviations: cfDNA, cell-free DNA; MBC, metastatic breast cancer; TTF, time to treatment failure; BCSS, breast cancer-specific survival. 
time to failure than patients with increasing cfDNA ESR 1 mutations and these differences were significant by log-rank test $(P=0.0033)$. A total of 3 out of 12 patients with increasing cfDNA ESR 1 mutations were treated with chemotherapy. In BCSS analysis, there was no significant difference among the patients with and without increasing cfDNA ESR 1 mutations $(P=0.22)$.

\section{Representative clinical courses}

Four representative examples of changes in cfDNA ESR 1 mutations during the clinical course are highlighted below. During the tracking cfDNA ESR 1 mutations ratios, case 75 and case 118 were treated with endocrine therapy and case 58 and case 77 were treated with chemotherapy (Figure 4A, 4B). The existence of ESRl mutations in MBC tissue samples were analyzed previously [21].

In case 75 , clinical metastasis was detected at 51 months after primary surgery. She then received systemic treatment with 9 different therapies including 5 endocrine therapies before the first blood draw. A metastatic chest wall tumor, which was biopsied before the first blood draw, showed ESR1 Y537S beyond the selected cut-off level. Analysis of cfDNA identified ESR 1 mutations in the plasma sample; ESR 1 Y 537N ratio was significantly increased in the third and the fourth blood draw in comparison with that in the first blood draw. Conversely, ESR1 D538G ratio was significantly decreased in the fourth blood draw in comparison with that in the first blood draw. ESR1 Y537S was slightly increased over the first blood draw and ESR1 Y537C was not detected at any time-point. In the same blood samples, CEA and CA15-3 were gradually increased over the first blood draw. Hormonal therapy was effective at first, but she was not response to any endocrine therapies after the second blood draw. In case 118, axillary lymph node metastasis was detected at 70 months after primary surgery. She then received 5 systemic therapies including 3 endocrine therapies before the first blood draw. Metastatic axillary lymph nodes, which were collected at the same time as the second blood draw, did not have any ESR1 mutations. Analysis of cfDNA identified ESR1 mutations in the plasma sample; ESR 1 Y537N ratio in the second blood draw was significantly increased in comparison with the first blood draw, but in the third blood draw was decreased to the level of the first blood draw. Both ESR1 Y537S and D538G ratio remained at the same level throughout the treatment period and ESR1 Y537C was not detected at any time-point. In the same blood samples, CEA and CA15-3 showed that they decreased during the treatment period. About the effect of endocrine therapy, she was not response to letrozole after the first blood draw, but she was response to exemestane following the second blood draw. Interestingly, ethinyl estradiol (EE2) had been effective for almost one year following the third blood draw (Figure 4A).

Case 58 was diagnosed as stage IV invasive ductal carcinoma and had received 3 endocrine therapies before the first blood draw, but he did not receive endocrine therapies after the first blood draw. A metastatic bone tumor, which was biopsied before the first blood draw, did not have any ESR1 mutations. Analysis of cfDNA identified ESR1 mutations in the plasma sample; ESR 1 mutations tended to decrease after the first blood draw, but cfDNA ESR1 Y537S ratio in the third blood draw was significantly increased in comparison with that in the first blood draw. In the same blood samples, tumor markers tended to decrease after the first blood draw, but CEA in the fourth blood draw was slightly increased. Any chemotherapy was not effective after the first blood draw. Case 77 was diagnosed as stage IV invasive ductal carcinoma and had received 8 systemic therapies including 6 endocrine therapies before the first blood draw. Interestingly, a metastatic bone tumor, which was biopsied after the third blood draw, did not have any ESR 1 mutations. Analysis of cfDNA identified ESR1 mutations in the plasma sample; ESR1 Y537S and D538G ratio in the third blood draw were significantly increased in comparison with that in the first blood draw. Neither ESR1 Y537N nor Y537C were detected at any time-point. In the same samples, CEA tended to increase after the first blood draw and CA15-3 was slightly decreased in the last blood draw. Any endocrine therapy was not effective after the first blood draw, but he was response to paclitaxel (Figure 4B).

\section{DISCUSSION}

The aim of this retrospective study was to investigate changes in cfDNA ESR 1 recurrent mutations in codons 537 and 538 with treatment in PBC and MBC patients using next-generation digital PCR platforms with a high level of sensitivity and specificity. The subjects of this serial study were a total of 77 women with $\mathrm{PBC}$ and 42 women with MBC. In looking at the number of dots plotted in Figure S1, S2 and Table S1, it appears that the majority if not all of the cases had some quantified value for one or more ESR 1 mutations. In addition, some untreated patients with $\mathrm{PBC}$ had detectable ESR1 mutations in their plasma, which were not consistent with what it is known from the literature: ESR1 LBD mutations are extremely rare in the early setting and can be identified in a significant proportion of MBC patients that have been exposed to AIs. The biggest reason is that, as our past history of publications reported, we had to use exceptionally high cutoffs to call a mutation because we took each cutoff of positive droplets widely to reduce bias by the rater. To solve this problem, we revised them 
by comparing 2-dimensional amplitudes of the same patient and used the PBC samples as a training set to establish the minimum cutoff for determining increases in ESR1 mutation fraction.
Our study generated several interesting results with potential therapeutic implications. Firstly, we demonstrated that blood can be a sensitive source for the detection of ESR 1 mutations using ddPCR as several other

A
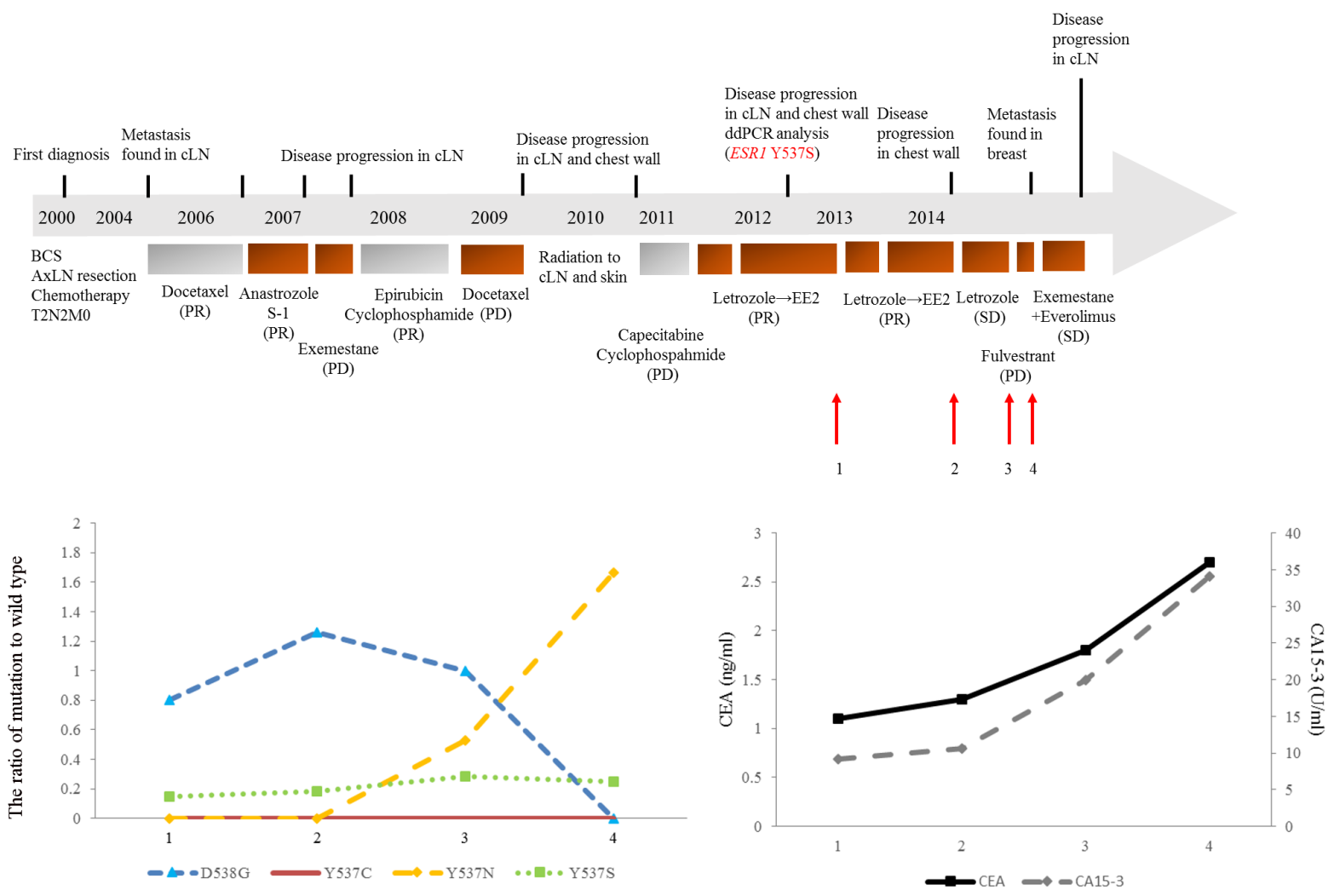

Case 75
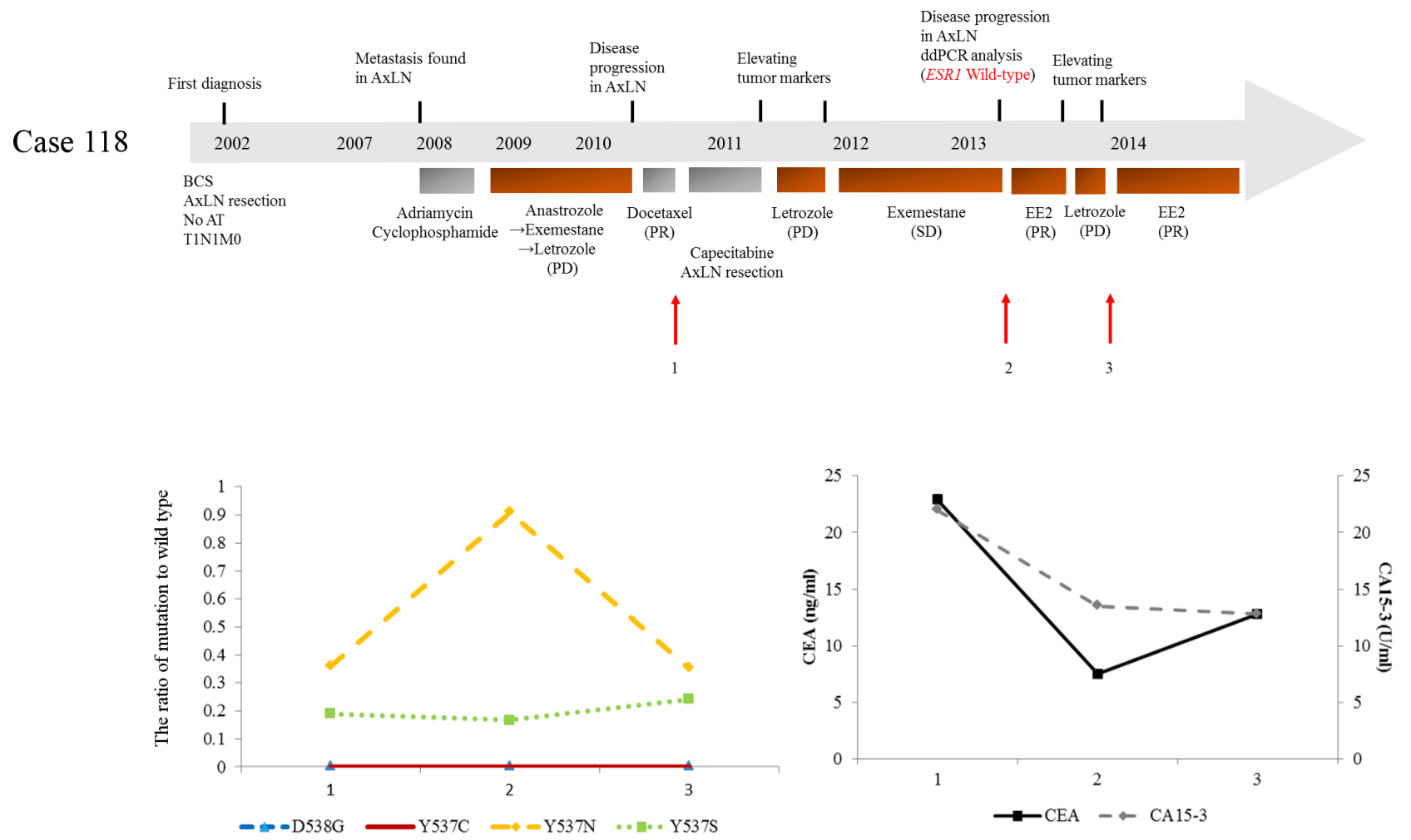
$\mathrm{B}$

Case 58
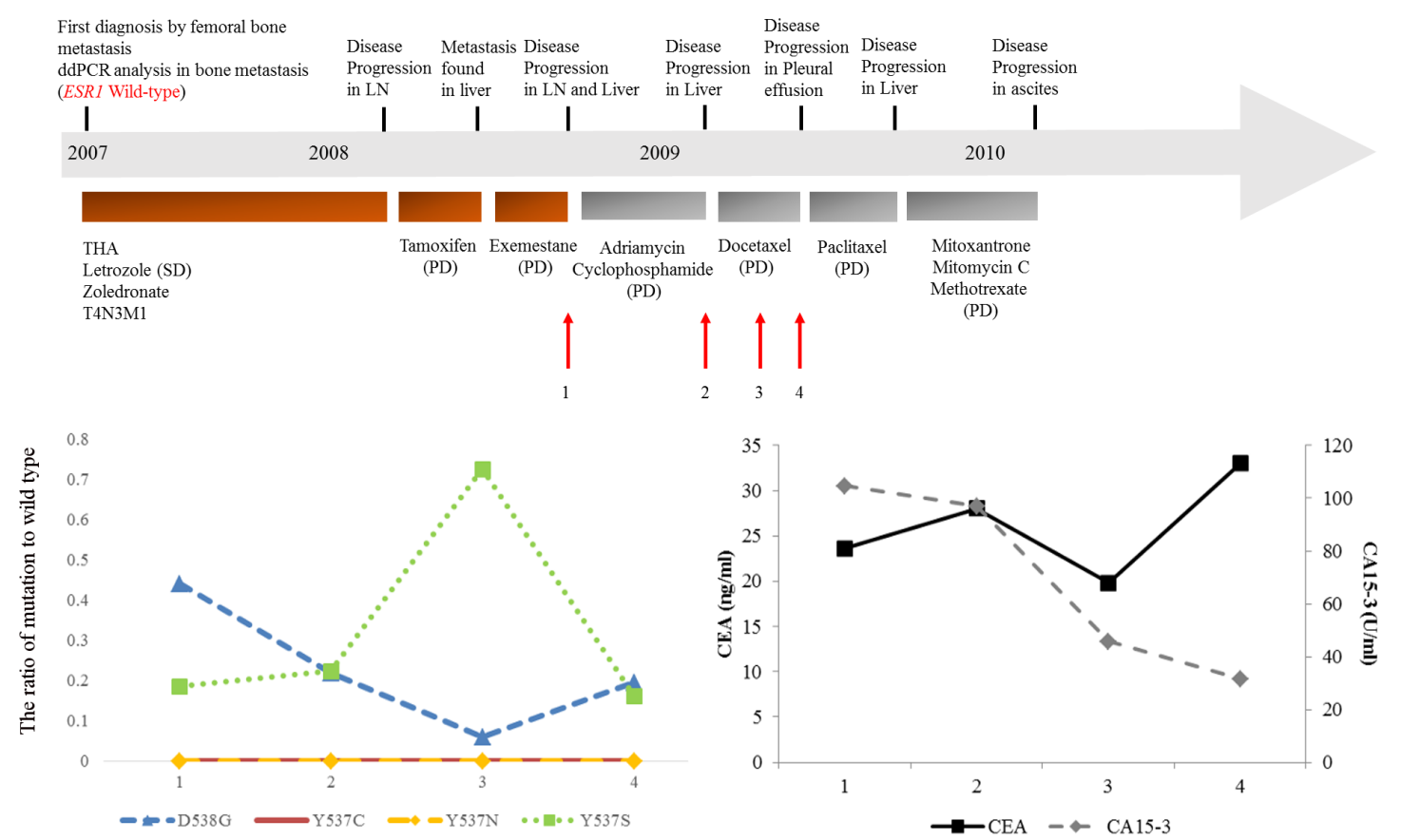

Case 77


Figure 4: (A, B) show the clinical timelines for ER-positive MBC patients with increasing cfDNA ESR1 mutations quantified using ddPCR. Patients' histories of clinical treatment from first diagnosis are shown in the upper part. Each bar represents the timeline of treatment. Plasma levels of each cfDNA ESRI mutation are shown in the lower left and levels of tumor markers are shown in the lower right. During the tracking cfDNA ESR 1 mutations ratio, case 75 and case 118 were treated with endocrine therapy (A) and case 58 and case 77 were treated with chemotherapy (B). (A) Case 75 had increasing cfDNA ESR1 Y537N ratio and decreasing cfDNA ESR1 D538G during treatment and Case 118 had increasing cfDNA ESR 1 mutations in the first blood draw, but not in the third blood draw. (B) Case 58 and case 77 both showed increases in cfDNA ESR1 mutations not in the second blood draw, but in the third blood draw. The existence of ESR1 mutations in MBC tissue samples were analyzed previously [21]. Abbreviations; cLN, cervical lymph node; ddPCR, droplet digital polymerase chain reaction; BCS, breast conserving surgery; AxLN, axial lymph node; S-1, an oral fluoropyrimidine; PR, partial response; PD, progressive disease; SD, stable disease; EE2, ethinyl estradiol, THA, total hip arthroplasty; CEF, cyclophosphamide, epirubicin, and fluorouracil. 
groups have reported $[9-11,15,18]$. Secondly, the ratio of cfDNA ESR1 mutations appeared to change during treatment. Increases in cfDNA ESR1 mutations were observed in 13 samples of cfDNA from 12 (28.6\%) out of $42 \mathrm{MBC}$ patients (Table 2 and Figures 2, 3A). Among these 12 patients, 6 patients $(50 \%)$ each had increasing cfDNA ESR 1 Y $537 \mathrm{~S}$ and Y537N, and 2 patients (16.7\%) had increasing cfDNA ESR1 D538G. We found that case 18 , case 44 , and case 118 showed increases in cfDNA ESR1 mutations ratio in the second blood draw, but not in the third blood draw. Conversely, case 58, case 77, and case 89 showed increases in cfDNA ESR1 mutations ratio not in the second blood draw, but in the third blood draw. Sequential increases in cfDNA ESR1 Y537N were observed in case 75 (Table 2 and Figure 4). This finding raises the possibility that cfDNA ESR 1 mutations fluctuate easily as a result of treatment, compared with tumor tissue. Thus, there is a need to develop non-invasive methods to quickly assess mutational profiles across multiple metastases from an individual patient. Third, our results may support the previous hypothesis that ESR1 mutations may be selected for after progression on AI therapy [5-7, 18]. In our study, a total of 11 out of 12 MBC patients with increasing ESR 1 mutations had been exposed to AIs for a long period. Interestingly, case 27, who had not been treated with AIs, had increasing cfDNA ESR1 Y537S and showed a poor response to treatment with anastrozole (Table 2). Fourth, we demonstrate that increasing cfDNA ESR1 mutations may be a poor predictor of post-treatment outcome. Of note, the higher the rate of ESR1 mutations following therapy, the poorer response to treatment was. cfDNA ESRI mutations showed dynamic changes across serial plasma samples in 13 cfDNA samples from a total of 12 out of $42 \mathrm{MBC}$ patients $(28.6 \%)$. A total of $10(83.3 \%)$ out of $12 \mathrm{MBC}$ patients with increasing $E S R 1$ mutations were not response to any treatments (Table 2 and Figure $3 \mathrm{~A}$ ). In survival analysis, increasing numbers of cfDNA ESR1 mutations may predict a shorter duration of post endocrine therapy effectiveness $(P=0.0033)$, but was not associated with BCSS (Figure 3B, 3C). This results had the possibility that cases with an increase in total cfDNA (where most of the increase was assumed to be coming from an increasing tumor burden [24-26]) had worse survival, but we could not find a correlation between the quantity of cfDNA and the frequency of each ESR 1 mutation. Therefore, our data on ESR1 mutation presented here was independent on tumor burdens. Finally, two cases with increases in cfDNA ESR1 mutations responded to treatment as follows; case 72-2 and case 118-2 were response to EE2 (Table 2 and Figure 4). This result may suggest that treatments different from conventional endocrine therapy in mechanism affect endocrine-resistant breast cancer [27, 28]. The number of $\mathrm{PBC}$ and $\mathrm{MBC}$ cases positive for each mutation should be presented clearly, but this was not provided in this study. The best way to provide the number of PBC and
MBC cases positive for each mutation is compared the results of ddPCR with that of NGS, but we were not able to extract enough DNA to use for analysis of NGS. Even if we set cutoff using synthetic templates, it was challenging because there was a difference in distribution of droplets between synthetic templates and clinical samples. Additionally, in many articles that analyzed clinical samples using ddPCR, it seems to be difficult to judge positive droplets in 2-dimensional amplitude. Therefore, we mainly analyzed how each ESR1 mutation changed by treatment in the same people.

The present study has limitations. This was a retrospective, single-institute study, and was prone to selection bias. Although the correlation of ESR1 mutations between tumor tissue and plasma is closely associated with medical history of endocrine therapy, this studied population is heterogeneously treated and we had insufficient data to examine whether ESRI mutation detection is dependent on specific hormone therapies or not. The samples used in this study were obtained for biobanking. Therefore, a time from blood draw to spinning, freezing plasma and then thawing may affect the variability of the data.

In conclusion, our study demonstrates that ddPCR monitoring of recurrent ESR1 mutations in cfDNA of breast cancer patients is feasible and is a useful method of providing relevant predictive information.

\section{MATERIALS AND METHODS}

\section{Patients and breast cancer tissues}

A total of 119 patients (253 plasma samples) with breast carcinoma, treated at Kumamoto University Hospital between 2004 and 2014, were enrolled in this study. Cases were selected if archival plasma samples were available from $\mathrm{PBC}$ before and after treatment and from $\mathrm{MBC}$ gathered more than twice at the time of progression. Informed consent was obtained from all patients before biopsy or surgery. The Ethics Committee of Kumamoto University Graduate School of Medicine (Kumamoto, Japan) approved the study protocol. Adjuvant and neoadjuvant treatment was administered in accordance with the recommendations of the St. Gallen international expert consensus on the primary therapy of early breast cancer [29-31]. The treatment of MBC patients was performed in accordance with the National Comprehensive Cancer Network Clinical Practice Guidelines in Oncology [32]. Patients were examined at the Kumamoto University Hospital or affiliated hospitals every 3 months for 5 years and every year thereafter. Recurrence was defined as the identification of positive spots by physical examination and/or by imaging diagnosis during the follow-up period. Metastatic patients were assessed monthly for clinical response, which was defined according to the Response Evaluation Criteria in Solid Tumors as complete response 
(CR), partial response (PR), stable disease (SD), or progressive disease (PD). We defined the presence of $\mathrm{CR}, \mathrm{PR}$, and long $\mathrm{SD}$ as responder and all other clinical responses as non- responder.

\section{Sample preparation}

Blood collected in EDTA K2 tubes was processed as soon as possible and was centrifuged at $3000 \mathrm{rpm}$ for $10 \mathrm{~min}$, with plasma stored in freezers until DNA extraction. DNA was extracted from $200 \mu \mathrm{l}$ of aliquots of plasma using the PureLink ${ }^{\circledR}$ Viral RNA/DNA Mini Kit (ThermoFisher scientific, Waltham, MA USA) according to the manufacturer's instructions. All DNA extracts were quantified using a NanoDrop 2000 spectrometer (NanoDrop Technologies, Wilmington, DE, USA) and purity was determined from the A260/A280 absorbance ratios.

\section{Analysis of ESR1 mutations by ddPCR}

The ddPCR assay for the detection of the variant types of amino acids 537 and 538 in ESR1 exon 8 consisted of a pair of primers and two TaqMan minor groove binding probes, as described previously, and this assay was carried out in the same sample twice using the QX200 ${ }^{\mathrm{TM}}$ Droplet Digital $^{\mathrm{TM}}$ PCR System (Bio-Rad laboratories, Hercules, CA, USA) as described previously [21]. The PCR data were quantified as copies/ $\mu$ using QuantaSoft $^{\mathrm{TM}}$ software (Bio-Rad laboratories). The ddPCR method had been optimized by comparative analysis of a dilution series of synthetic copies of each indicated mutant ESR1 oligonucleotide, as reported previously [21]. In addition, to be satisfied that the 4 assays have sufficiently good enough performance, we performed comparative analysis of the dilution series and crossreactivity of indicated synthetic each ESR1 mutation oligonucleotides of ESR1 Y537S, Y537N, Y537C, and D538G, in a background of wild-type normal human DNA (Figure S3). The dilution experiments were prepared by two-fold serial dilution of each synthetic ESR1 mutation stock oligonucleotide in a background of wild-type normal human DNA (TaqMan Control Genomic DNA) where the total DNA content of each ddPCR reaction was $20 \mathrm{ng}$ and "wild-type double" was $40 \mathrm{ng}$. The experiments for cross-reactivity between mutations were prepared by $5 \%$ each synthetic ESR1 mutation stock oligonucleotide in a background of wild-type normal human DNA where the total DNA content of each ddPCR reaction was $20 \mathrm{ng}$. We confirmed that this assay was able to detect each ESR1 mutant molecule in a background of wild-type normal human DNA with the lowest concentration and was not able to detect any false-positives in the wild-type normal human DNA.

\section{Probes and primers}

Immunohistochemical staining for estrogen receptor alpha $(\mathrm{ER} \alpha)$, progesterone receptor $(\mathrm{PgR})$, and human epidermal growth factor receptor 2 (HER2) staining, and $\mathrm{Ki} 67$ and the evaluation of them was described previously [33].

\section{Statistical analysis}

The nonparametric Mann-Whitney $U$ test and contingency analysis were adopted for statistical analysis of the associations between cfDNA ESR1 mutations ratio and clinicopathological factors, and between the differences with cfDNA ESR1 mutations ratio in the first blood sample. For TTF and BCSS, Kaplan-Meier method was used to estimate survival rates, and differences between survival curves were evaluated by the log-rank test. Differences were considered significant when a $P$-value $<0.05$ was obtained. All statistical analyses were two-sided and were performed using JMP software version 10.0.1 for Windows (SAS institute Japan, Tokyo, Japan).

\section{ACKNOWLEDGMENTS AND FUNDING}

This work was supported in part by a grant-in-aid (project numbers 26461952) for scientific research from the Ministry of Education, Science and Culture of Japan.

\section{CONFLICTS OF INTEREST}

All the authors declare that they have no actual, potential, or perceived conflict of interest with regard to the manuscript submitted for review.

\section{REFERENCES}

1. Iwase H. Current topics and perspectives on the use of aromatase inhibitors in the treatment of breast cancer. Breast Cancer. 2008; 15:278-290.

2. Baum M, Budzar AU, Cuzick J, Forbes J, Houghton JH, Klijn JG, Sahmoud T, Group AT. Anastrozole alone or in combination with tamoxifen versus tamoxifen alone for adjuvant treatment of postmenopausal women with early breast cancer: first results of the ATAC randomised trial. Lancet. 2002; 359:2131-2139.

3. Fuqua SA, Fitzgerald SD, Allred DC, Elledge RM, Nawaz Z, McDonnell DP, O'Malley BW, Greene GL, McGuire WL. Inhibition of estrogen receptor action by a naturally occurring variant in human breast tumors. Cancer Res. 1992; 52:483-486.

4. Weis KE, Ekena K, Thomas JA, Lazennec G, Katzenellenbogen BS. Constitutively active human estrogen receptors containing amino acid substitutions for tyrosine 
537 in the receptor protein. Mol Endocrinol. 1996; 10:1388-1398.

5. Robinson DR, Wu YM, Vats P, Su F, Lonigro RJ, Cao X, Kalyana-Sundaram S, Wang R, Ning Y, Hodges L, Gursky A, Siddiqui J, Tomlins SA, et al. Activating ESR1 mutations in hormone-resistant metastatic breast cancer. Nat Genet. 2013; 45:1446-1451.

6. Toy W, Shen Y, Won H, Green B, Sakr RA, Will M, Li Z, Gala K, Fanning S, King TA, Hudis C, Chen D, Taran T, et al. ESR1 ligand-binding domain mutations in hormoneresistant breast cancer. Nat Genet. 2013; 45:1439-1445.

7. Jeselsohn R, Yelensky R, Buchwalter G, Frampton G, Meric-Bernstam F, Gonzalez-Angulo AM, Ferrer-Lozano J, Perez-Fidalgo JA, Cristofanilli M, Gomez H, Arteaga CL, Giltnane J, Balko JM, et al. Emergence of constitutively active estrogen receptor-alpha mutations in pretreated advanced estrogen receptor-positive breast cancer. Clin Cancer Res. 2014; 20:1757-1767.

8. Oesterreich S, Davidson NE. The search for ESR1 mutations in breast cancer. Nat Genet. 2013; 45:1415-1416.

9. Sefrioui D, Perdrix A, Sarafan-Vasseur N, Dolfus C, Dujon A, Picquenot JM, Delacour J, Cornic M, Bohers E, Leheurteur M, Rigal O, Tennevet I, Thery JC, et al. Short report: Monitoring ESR1 mutations by circulating tumor DNA in aromatase inhibitor resistant metastatic breast cancer. Int J Cancer. 2015; 137:2513-9.

10. Wang T, Liu JH, Zhang J, Wang L, Chen C, Dai PG. A multiplex allele-specific real-time PCR assay for screening of ESR1 mutations in metastatic breast cancer. Exp Mol Pathol. 2015; 98:152-157.

11. Chu D, Paoletti C, Gersch C, VanDenBerg D, Zabransky D, Cochran R, Wong HY, Valda Toro P, Cidado J, Croessmann S, Erlanger B, Cravero K, Kyker-Snowman K, et al. ESR1 mutations in circulating plasma tumor DNA from metastatic breast cancer patients. Clin Cancer Res. 2016; 22:993-9.

12. Overman MJ, Modak J, Kopetz S, Murthy R, Yao JC, Hicks ME, Abbruzzese JL, Tam AL. Use of research biopsies in clinical trials: are risks and benefits adequately discussed? J Clin Oncol. 2013; 31:17-22.

13. Rothe F, Laes JF, Lambrechts D, Smeets D, Vincent D, Maetens M, Fumagalli D, Michiels S, Drisis S, Moerman C, Detiffe JP, Larsimont D, Awada A, et al. Plasma circulating tumor DNA as an alternative to metastatic biopsies for mutational analysis in breast cancer. Ann Oncol. 2014; 25:1959-1965.

14. Diehl F, Schmidt K, Choti MA, Romans K, Goodman S, Li M, Thornton K, Agrawal N, Sokoll L, Szabo SA, Kinzler KW, Vogelstein B, Diaz LA, et al. Circulating mutant DNA to assess tumor dynamics. Nat Med. 2008; 14:985-990.

15. Garcia-Murillas I, Schiavon G, Weigelt B, $\mathrm{Ng} \mathrm{C}$, Hrebien S, Cutts RJ, Cheang M, Osin P, Nerurkar A, Kozarewa I, Garrido JA, Dowsett M, Reis-Filho JS, et al.
Mutation tracking in circulating tumor DNA predicts relapse in early breast cancer. Sci Transl Med. 2015; 7:302ra133.

16. Higgins MJ, Jelovac D, Barnathan E, Blair B, Slater S, Powers P, Zorzi J, Jeter SC, Oliver GR, Fetting J, Emens L, Riley C, Stearns V, et al. Detection of tumor PIK3CA status in metastatic breast cancer using peripheral blood. Clin Cancer Res. 2012; 18:3462-3469.

17. Olsson E, Winter C, George A, Chen Y, Howlin J, Tang MH, Dahlgren M, Schulz R, Grabau D, van Westen D, Ferno M, Ingvar $\mathrm{C}$, Rose $\mathrm{C}$, et al. Serial monitoring of circulating tumor DNA in patients with primary breast cancer for detection of occult metastatic disease. EMBO Mol Med. 2015; 7:1034-1047.

18. Schiavon G, Hrebien S, Garcia-Murillas I, Cutts RJ, Pearson A, Tarazona N, Fenwick K, Kozarewa I, LopezKnowles E, Ribas R, Nerurkar A, Osin P, Chandarlapaty S, et al. Analysis of ESR1 mutation in circulating tumor DNA demonstrates evolution during therapy for metastatic breast cancer. Sci Transl Med. 2015; 7:313ra182.

19. Dawson SJ, Tsui DW, Murtaza M, Biggs H, Rueda OM, Chin SF, Dunning MJ, Gale D, Forshew T, MahlerAraujo B, Rajan S, Humphray S, Becq J, et al. Analysis of circulating tumor DNA to monitor metastatic breast cancer. N Engl J Med. 2013; 368:1199-1209.

20. Hindson CM, Chevillet JR, Briggs HA, Gallichotte EN, Ruf IK, Hindson BJ, Vessella RL, Tewari M. Absolute quantification by droplet digital PCR versus analog realtime PCR. Nat Methods. 2013; 10:1003-1005.

21. Takeshita T, Yamamoto Y, Yamamoto-Ibusuki M, Inao T, Sueta A, Fujiwara S, Omoto Y, Iwase H. Droplet digital polymerase chain reaction assay for screening of ESR1 mutations in 325 breast cancer specimens. Transl Res. 2015; 166:540-553.e2.

22. Takeshita T, Yamamoto Y, Yamamoto-Ibusuki M, Inao T, Sueta A, Fujiwara S, Omoto Y, Iwase H. Prognostic role of PIK3CA mutations of cell-free DNA in early-stage triple negative breast cancer. Cancer Sci. 2015; 106:1582-9.

23. Li S, Shen D, Shao J, Crowder R, Liu W, Prat A, He X, Liu S, Hoog J, Lu C, Ding L, Griffith OL, Miller C, et al. Endocrinetherapy-resistant ESR1 variants revealed by genomic characterization of breast-cancer-derived xenografts. Cell Rep. 2013; 4:1116-1130.

24. Catarino R, Ferreira MM, Rodrigues H, Coelho A, Nogal A, Sousa A, Medeiros R. Quantification of free circulating tumor DNA as a diagnostic marker for breast cancer. DNA Cell Biol. 2008; 27:415-421.

25. Zanetti-Dallenbach RA, Schmid S, Wight E, Holzgreve W, Ladewing A, Hahn S, Zhong XY. Levels of circulating cellfree serum DNA in benign and malignant breast lesions. Int J Biol Markers. 2007; 22:95-99.

26. Hashad D, Sorour A, Ghazal A, Talaat I. Free circulating tumor DNA as a diagnostic marker for breast cancer. J Clin Lab Anal. 2012; 26:467-472. 
27. Ellis MJ, Gao F, Dehdashti F, Jeffe DB, Marcom PK, Carey LA, Dickler MN, Silverman P, Fleming GF, Kommareddy A, Jamalabadi-Majidi S, Crowder R, Siegel BA. Lower-dose vs high-dose oral estradiol therapy of hormone receptorpositive, aromatase inhibitor-resistant advanced breast cancer: a phase 2 randomized study. JAMA. 2009; 302: 774-780.

28. Iwase H, Yamamoto Y, Yamamoto-Ibusuki M, Murakami KI, Okumura Y, Tomita S, Inao T, Honda Y, Omoto Y, Iyama KI. Ethinylestradiol is beneficial for postmenopausal patients with heavily pre-treated metastatic breast cancer after prior aromatase inhibitor treatment: a prospective study. Br J Cancer. 2013; 109:1537-1542.

29. Goldhirsch A, Wood WC, Gelber RD, Coates AS, Thurlimann B, Senn HJ. Meeting highlights: updated international expert consensus on the primary therapy of early breast cancer. J Clin Oncol. 2003; 21:3357-3365.
30. Goldhirsch A, Glick JH, Gelber RD, Coates AS, Thurlimann B, Senn HJ, Panel m. Meeting highlights: international expert consensus on the primary therapy of early breast cancer 2005. Ann Oncol. 2005; 16:1569-1583.

31. Goldhirsch A, Wood WC, Gelber RD, Coates AS, Thurlimann B, Senn HJ, th St. Gallen c. Progress and promise: highlights of the international expert consensus on the primary therapy of early breast cancer 2007. Ann Oncol. 2007; 18:1133-1144.

32. Gradishar WJ, Anderson BO, Blair SL, Burstein HJ, Cyr A, Elias AD, Farrar WB, Forero A, Giordano SH, Goldstein LJ, Hayes DF, Hudis CA, Isakoff SJ, et al. Breast cancer version 3.2014. J Natl Compr Canc Netw. 2014; 12:542-590.

33. Takeshita T, Omoto Y, Yamamoto-Ibusuki M, Yamamoto Y, Iwase H. Clinical significance of androgen receptor and its phosphorylated form in breast cancer. Endocr Relat Cancer. 2013; 20:L15-21. 